\title{
UNIT ROOT AND COINTEGRATION TESTING: GUEST EDITORS' INTRODUCTION
}

\author{
HELMUT LÜTKEPOHL \\ European University Institute \\ PaUlo M.M. RodRigues \\ University of Algarve
}

\section{BACKGROUND}

By pointing out the spurious regression problem, Granger and Newbold (1974) have shown the importance of stochastic trends in time series data in the context of linear regression models. At the time, removing trends by differencing was already common practice in univariate time series modeling as part of the Box-Jenkins approach (Box and Jenkins, 1976). These new developments, however, emphasized the importance of autoregressive (AR) unit roots and motivated the development of statistical procedures for their detection. Dickey and Fuller (1979) and Fuller (1976) were pioneers in developing tests for unit roots that became widely used. The foundation of asymptotic theory for regressions involving stochastic trends was led by Phillips $(1986,1987)$ with the introduction of the functional limit theory, weak convergence methods, convergence to stochastic integrals, nonparametric unit root testing, and continuous record asymptotics. Phillips and Durlauf (1986) extended some of these results to the multivariate setting by presenting the multivariate invariance principles and the asymptotic theory of multivariate nonstationary and cointegrating regressions. These contributions provided the asymptotic tools that have served as the basis for most of the limit results derived in the context of unit root nonstationarity, and they have stimulated extensive subsequent research.

Over the last 30 years many other important contributions were made, of which the following are of particular relevance. Augmented Dickey-Fuller (ADF) tests

\footnotetext{
We are grateful to Peter Phillips for proposing a special issue of Econometric Theory for papers from our conference Unit Root and Cointegration Testing. We thank all participants of the conference who contributed their papers to this special issue. We are also very grateful to those colleagues who agreed to serve as referees for the papers. They not only provided generous help through comments but also respected our rather tight deadlines. We are grateful to all those who helped us to complete the special issue unusually fast. To protect their identities, we do not list them here. They will be included in the general list of referees for Econometric Theory. Our conference would not have been possible without the generous financial support of a number of sponsors. We are grateful to the Bank of Portugal, to the Portuguese Science Foundation (FCT), to the Luso-American Foundation for Development (FLAD), and to the Journal of Applied Econometrics for their financial support. Address correspondence to Helmut Lütkepohl, Department of Economics, European University Institute, Via della Piazzola 43, I-50133 Firenze, Italy; e-mail: helmut.luetkepohl@eui.it.
} 
were initially designed for finite-order AR processes; however, extensions to more general processes became desirable as the finite-order AR framework was considered too restrictive for a number of situations. Infinite-order AR (e.g., Said and Dickey, 1984) and nonparametric extensions (e.g., Phillips and Perron, 1988; Schmidt and Phillips, 1992) were proposed. Also the deterministic term considered in the test regression has played an important role in the literature. The asymptotic distribution of the ADF test depends on the deterministic terms considered, and it is generally not invariant to misspecifications of these terms. Therefore tests with deterministic terms other than the original constant and linear trend components were considered. For instance, given the empirical features of many macroeconomic and financial time series, level shifts and breaks in trend slopes were allowed for. Initially the break dates were assumed to be known (e.g., Perron, 1989), and later extensions to the case of unknown break points were considered (see, e.g., Zivot and Andrews, 1992; Perron and Vogelsang, 1992; Saikkonen and Lütkepohl, 2002). Further refinements of the unit root test procedures include, for example, ADF test versions with improved power properties (e.g., Elliott, Rothenberg, and Stock, 1996; Shin and So, 2001) and unit root tests robust to conditional heteroskedasticity (e.g., Ling and Li, 2003).

The ADF procedure is designed to test the null hypothesis of a unit root against the stationarity alternative. However, its limited small-sample power may lead to the detection of unit roots when these are absent in the data generation process (DGP). Thus, a different strand of tests was developed that considers instead the null hypothesis of stationarity against a unit root and that may serve as a useful complement for confirmation analysis of the ADF approach. A popular early version of such tests was developed by Kwiatkowski, Phillips, Schmidt, and Shin (1992) and has since been used under the name of KPSS test.

Other unit root tests have also been proposed for several other situations of practical interest. For example, tests for seasonal unit roots were proposed by Hylleberg, Engle, Granger, and Yoo (1990) and Rodrigues and Taylor (2004) inter alia; tests for fractional integration were developed by Robinson (1991) and others; tests for unit roots in panel data were presented, for instance, by Breitung and Meyer (1994) and Levin, Lin, and Chu (2002); and tests for unit roots in nonlinear contexts, such as self-exciting autoregressive (SETAR) and smooth transition AR (STAR) processes were introduced by Caner and Hansen (2001), Kapetanios, Snell, and Shin (2003), and others.

Unit root properties are, however, not only important for modeling univariate time series. The theory of cointegration initiated by Granger (1981) and Engle and Granger (1987) extends the unit root literature to the multivariate context and shows that stochastic trends are also of utmost importance in modeling systems of time series variables. Given the greater diversity of multivariable models it is not surprising that the range of proposals for cointegration testing is extensive and diverse. One may distinguish between single equation and system tests. The former may be based on ADF-type tests and thus extend 
the full range of ADF-type proposals, whereas system tests may generalize the ADF approach to a multivariate setting as in Johansen (1988, 1995). A large range of similar systems proposals is reviewed in Hubrich, Lütkepohl, and Saikkonen (2001). Again these ideas can be extended to seasonal data (e.g., Johansen and Schaumburg, 1999), panel data (e.g., Banerjee, 1999), nonlinear models (e.g., Balke and Fomby, 1997), and fractionally integrated series with long-range dependence (e.g., Breitung and Hassler, 2002). In short, unit root and cointegration testing have become a rapidly expanding playground for theoretical and applied econometricians. The latter have posed problems related to specific data and models that the former have tried to address.

In fact, research in this area is still very active, and new research frontiers have emerged over the last few years, reasons that motivated us to organize a conference on unit root and cointegration testing. A small workshop was originally envisaged. Very rapidly, we realized, however, that there was significant interest by the profession with a large body of research still developing in the field of unit root and cointegration testing. It was a pleasant surprise that an overwhelming number of researchers wanted to take part in the event, resulting in a medium-sized conference that took place at the Faculty of Economics of the University of Algarve in Faro, Portugal, from September 29 to October 1, 2005. There were 89 participants from all over the world who contributed to this very stimulating and memorable event. Sixty-two papers were presented at the conference, 23 of which were in plenary sessions and the remaining ones in two poster sessions. The detailed conference program follows these introductory remarks.

Given the substantial interest in the topic of unit root and cointegration testing, we decided to collect some of the papers in a special journal issue. We are very grateful to Peter Phillips for not only participating in the conference but also providing us with the opportunity to edit a special issue of Econometric Theory. We gladly accepted and asked all plenary speakers to contribute their papers. Luckily many of them agreed and submitted their papers by the end of October 2005. As special issue editors we adopted the usual editorial procedure of Econometric Theory. Ten papers survived the reviewing and revision procedure within our tight framework of deadlines. They are now included in this issue.

\section{CONTENTS}

Werner Ploberger derives a general result on the admissibility of tests that has the intriguing implication that ADF unit root tests in models without deterministic term are asymptotically inadmissible. In other words, there must be a unit root test with better power than the ADF tests. Given the low power of these tests, which is often bothersome in applied work, this result is clearly of great interest. Unfortunately, the proof is not constructive in that only the existence of a more powerful test is demonstrated but not the test itself.

In the second paper, Giuseppe Cavaliere and Robert Taylor develop bootstrap unit root tests for time series with nonstationary volatility. Given that con- 
ventional unit root tests are unreliable in the presence of this type of behavior, because they have nonpivotal asymptotic null distributions, Cavaliere and Taylor resort to a wild bootstrap to develop an approach to unit root testing that is valid in the presence of a wide class of permanent variance changes that includes single and multiple volatility change processes as special cases. They observe through Monte Carlo simulations that the bootstrap tests perform very well even in small samples.

Fabio Busetti and Andrew Harvey examine various tests that assess whether a time series model requires a slope component. They show that a simple $t$-test on the mean of first differences achieves high power against the alternative hypothesis of a stochastic nonstationary slope and also against a purely deterministic slope. Using both local limiting power arguments and finite-sample Monte Carlo results, this $t$-test is compared with the nonparametric tests of Vogelsang (1998) and with a modified stationarity test. Busetti and Harvey observe that the $t$-test performs well particularly when fitting a parametric model to the data. They further observe that as a test for the null hypothesis of a stochastic slope its contribution may be limited by an inability to reject a small deterministic slope.

Jörg Breitung and Samarjit Das consider unit root testing in panels with a factor structure. Specifically, various tests of the unit root hypothesis in panels where cross-section dependence is due to common dynamic factors are evaluated. Three specific situations are considered: (i) the common factors and idiosyncratic components are both nonstationary; (ii) the common component is $I(1)$, and the idiosyncratic component is stationary (the case of cross-unit cointegration); and (iii) the idiosyncratic components are $I(1)$, but the common factors are stationary. The overall conclusions drawn for each case from the comparison of application of ordinary least squares (OLS) and generalized least squares (GLS) based procedures are that (i) in the first scenario, the test statistics based on GLS possess a standard normal limiting distribution, whereas OLS based test statistics are invalid; (ii) in the second case both the OLS and the GLS statistics fail; and (iii) finally in the last scenario they observe that the OLS based test statistics are severely biased, whereas the GLS based test statistics remain asymptotically valid.

For seasonal data periodic models with a potentially different set of parameters for each season are sometimes useful. Variables generated by periodic vector autoregressive models can also be integrated and in fact cointegrated. Tomas del Barrio Castro and Denise Osborn consider such models. They derive some important properties of these models and also contrast them with models for seasonally integrated variables. Moreover, they derive cointegration tests for periodically integrated series and investigate their asymptotic and small-sample properties.

The next four papers address issues related to long memory and fractional integration and cointegration. David Harris, Brendan McCabe, and Stephen Leybourne use higher order sample autocorrelations to construct a semiparametric 
test of the null hypothesis of short memory. Under the null, the test statistic has a standard normal distribution and hence does not depend on nuisance parameters. It provides a consistent test against long memory alternatives. They also explore the finite-sample properties of their test by means of a simulation study.

Matei Demetrescu, Vladimir Kuzin, and Uwe Hassler propose a new regression based, lag augmented version of the Lagrange multiplier test originally proposed by Robinson (1991) for integration against fractional alternatives. They provide a broad analysis by allowing (i) the short memory component to follow a general linear process; (ii) the innovations driving this process to be martingale differences with eventual conditional heteroskedasticity; and (iii) the number of lags to grow with the sample size, thus approximating the general linear process. Demetrescu et al. also investigate, through Monte Carlo simulation, the usefulness of their asymptotic results in finite samples and present an interesting analysis of several model selection strategies.

Javier Hualde and Carlos Velasco consider testing for fractional cointegration in a set of variables and derive tests with a limiting $\chi^{2}$ distribution that account for short-run correlation in a nonparametric way. They obtain asymptotic results under weak conditions and explore the small-sample properties in a Monte Carlo study.

James Davidson and Nigar Hashimzade compare time domain and frequency domain representations of fractionally integrated processes and show that different representations are not equivalent. They derive weak convergence results for such processes and introduce fractional Brownian motion in this context.

Finally, in the last paper of this special issue Pentti Saikkonen establishes a general stability result for error correction models with nonlinear short-run dynamics. Such results are the basis for deriving inference methods for this type of models and are therefore relevant in the context of this special issue.

\section{REFERENCES}

Balke, N.S. \& T.B. Fomby (1997) Threshold cointegration. International Economic Review 38, 627-645.

Banerjee, A. (1999) Panel data unit roots and cointegration: An overview. Oxford Bulletin of Economics and Statistics 61, 607-630.

Box, G.E.P. \& G.M. Jenkins (1976) Time Series Analysis: Forecasting and Control. Holden-Day.

Breitung, J. \& U. Hassler (2002) Inference on the cointegration rank in fractionally integrated processes. Journal of Econometrics 110, 167-185.

Breitung, J. \& W. Meyer (1994) Testing for unit roots in panel data: Are wages on different bargaining levels cointegrated? Applied Economics 26, 353-361.

Caner, M. \& B.E. Hansen (2001) Threshold autoregression with a unit root. Econometrica 69, 1555-1596.

Dickey, D.A. \& W.A. Fuller (1979) Estimators for autoregressive time series with a unit root. Journal of the American Statistical Association 74, 427-431.

Elliott, G., T.J. Rothenberg, \& J.H. Stock (1996) Efficient tests for an autoregressive unit root. Econometrica 64, 813-836.

Engle, R.F. \& C.W.J. Granger (1987) Cointegration and error correction: Representation, estimation and testing. Econometrica 55, 251-276. 
Fuller, W.A. (1976) Introduction to Statistical Time Series. Wiley.

Granger, C.W.J. (1981) Some properties of time series data and their use in econometric model specification. Journal of Econometrics 16, 121-130.

Granger, C.W.J. \& P. Newbold (1974) Spurious regressions in econometrics. Journal of Econometrics 2, 111-120.

Hubrich, K., H. Lütkepohl, \& P. Saikkonen (2001) A review of systems cointegration tests. Econometric Reviews 20, 247-318.

Hylleberg, S., R.F. Engle, C.W.J. Granger, \& B.S. Yoo (1990) Seasonal integration and cointegration. Journal of Econometrics 44, 215-238.

Johansen, S. (1988) Statistical analysis of cointegration vectors. Journal of Economic Dynamics and Control 12, 231-254.

Johansen, S. (1995) Likelihood-Based Inference in Cointegrated Vector Autoregressive Models. Oxford University Press.

Johansen, S. \& E. Schaumburg (1999) Likelihood analysis of seasonal cointegration. Journal of Econometrics 88, 301-339.

Kapetanios, G., A. Snell, \& Y. Shin (2003) Testing for a unit root in the nonlinear STAR framework. Journal of Econometrics 112, 359-379.

Kwiatkowski, D., P.C.B. Phillips, P. Schmidt, \& Y. Shin (1992) Testing the null of stationarity against the alternative of a unit root: How sure are we that the economic time series have a unit root? Journal of Econometrics 54, 159-178.

Levin, A., C.F. Lin, \& C.S.J. Chu (2002) Unit root tests in panel data: Asymptotic and finitesample properties. Journal of Econometrics 108, 1-24.

Ling, S. \& W.K. Li (2003) Asymptotic inference for unit root processes with GARCH(1,1) errors. Econometric Theory 19, 541-564.

Perron, P. (1989) The great crash, the oil price shock, and the unit root hypothesis. Econometrica 57, 1361-1401.

Perron, P. \& T.J. Vogelsang (1992) Nonstationarity and level shifts with an application to purchasing power parity. Journal of Business \& Economic Statistics 10, 301-320.

Phillips, P.C.B. (1986) Understanding spurious regressions in econometrics. Journal of Econometrics 33, 311-340.

Phillips, P.C.B. (1987) Time series regression with a unit root. Econometrica 55, 277-301.

Phillips, P.C.B. \& S.N. Durlauf (1986) Multiple time series regression with integrated processes. Review of Economic Studies 53, 473-495.

Phillips, P.C.B. \& P. Perron (1988) Testing for a unit root in time series regressions. Biometrika 75, 335-346.

Robinson, P.M. (1991) Testing for strong serial correlation and dynamic conditional heteroskedasticity in multiple regression. Journal of Econometrics 47, 67-84.

Rodrigues, P.M.M. \& A.M.R. Taylor (2004) Alternative estimators and unit root tests for seasonal autoregressive processes. Journal of Econometrics 120, 35-73.

Said, S.E. \& D.A. Dickey (1984) Testing for unit roots in autoregressive-moving average models of unknown order. Biometrika 71, 599-607.

Saikkonen, P. \& H. Lütkepohl (2002) Testing for a unit root in a time series with a level shift at unknown time. Econometric Theory 18, 313-348.

Schmidt, P. \& P.C.B. Phillips (1992) LM tests for a unit root in the presence of deterministic trends. Oxford Bulletin of Economics and Statistics 54, 257-287.

Shin, D.W. \& B.S. So (2001) Recursive mean adjustment and tests for unit roots. Journal of Time Series Analysis 22, 595-612.

Vogelsang, T.J. (1998) Trend function hypothesis testing in the presence of serial correlation. Econometrica $66,123-148$.

Zivot, E. \& D. Andrews (1992) Further evidence on the great crash, the oil-price shock, and the unit-root hypothesis. Journal of Business \& Economic Statistics 10, 251-270. 